\title{
Evaluation of Corneal Endothelium in Middle-Aged Keratoconus Eyes
}

\section{Emine Doğan ( $\nabla$ dremined@yahoo.com )}

Sakarya Universitesi Egitim ve Arastirma Hastanesi https://orcid.org/0000-0002-6505-3328

\section{Burçin Çakır}

Sakarya Training and Research Hospital: Sakarya Universitesi Egitim ve Arastirma Hastanesi

\section{Nilgün Aksoy}

Sakarya Training and Research Hospital: Sakarya Universitesi Egitim ve Arastirma Hastanesi

Gürsoy Alagöz

Sakarya Training and Research Hospital: Sakarya Universitesi Egitim ve Arastirma Hastanesi

\section{Research Article}

Keywords: Corneal endothelial cell, Keratoconus, Specular microscopy, Topography

Posted Date: April 15th, 2021

DOl: https://doi.org/10.21203/rs.3.rs-409332/v1

License: (9) This work is licensed under a Creative Commons Attribution 4.0 International License. Read Full License 


\section{Abstract \\ Purpose}

To investigate the corneal endothelial cell parameters and to evaluate the correlation with corneal topographic parameters in middle-aged non-treated keratoconus $(\mathrm{KC})$ patients.

\section{Materials and Methods}

Thirty-six eyes of $21 \mathrm{KC}$ patients in the middle decade (4th-5th) and age-gender matched 36 healthy eyes were included. Topographic parameters [(K1, K2 Sim K, central, thinnest pachymetry, anterior chamber depth (ACD)] were obtained with Galillei double scheimpflug analyzer. Patients were divided into stages according to mean keratometric values (Mild < 45D,Moderate 45-52D, Severe > 52D, Advanced $>62 \mathrm{D}$ ). Endothelial cell density (ECD), coefficient of variation (CV) of cell areas and hexagonal cell percentage (HCP) obtained with specular microscopy were recorded.Corneal topography and specular microscopy parameters were compared between $\mathrm{KC}$ and healthy eyes. The correlation between topographic and specular microscopy parameters were analyzed.

\section{Results}

The mean age of the patients was $38.6 \pm 6.0$ and $37.8 \pm 4.2$ years in the $K C$ and control group, respectively. Age and gender were statistically similar between the groups. ECD was $2772 \pm 17$ in the KC group and $2741 \pm 30$ cells / $\mathrm{mm}^{2}$ in the control group, and there was no statistical difference between the groups (p: 0.621). HCP was $63.5 \pm 7.2,67.4 \pm 5.2$ in KC and healthy eyes, respectively (p: 0.014 ); CV was $30.7 \pm 5.2$ and $28.6 \pm 3.4$, respectively ( $p: 0.058$ ). Specular microscopy parameters were not statistically different according to $\mathrm{KC}$ stage. $\mathrm{K} 1, \mathrm{~K} 2$,SimK, CCT, ACD did not correlate with ECD in patients.

\section{Conclusion}

Our results showed that endothelial cell morphology is significantly affected in middle-aged KC patients who have not been treated.

\section{Introduction}

Keratoconus (KC) characterized by progressive thinning and asymmetric protrusion of the cornea; causes irregular astigmatism and visual disturbance. It is usually diagnosed in adolescence and tends to progress for $7-8$ years and then stabilizes. ${ }^{1-3}$

Although its etiology is not known exactly; it has been reported that factors such as genetics, mechanical trauma, and enzymatic changes in the cornea have an important role. ${ }^{4}$ With the effect of these factors, 
almost all layers of the cornea are affected histopathologically. In various histological studies, epithelial basement membrane fragmentation, tears in the bowman layer, stromal thinning and scarring have been reported in $\mathrm{KC}$ cases. ${ }^{3-5}$ The endothelial layer in these cases has been analyzed in various studies with confocal and specular microscopy. In confocal microscopy studies, flattening of the basal epithelial cells; disturbances in the organization of stromal keratocyte, thickening of the intracorneal nerves, extension and elongation of the endothelial cells in the region of the cone apex, 7-10 fold growth in endothelial cells adjacent to the hydrops cite have been reported. ${ }^{6-8}$ Conflicting results have been reported in specular microscopy studies. Some publications reported lower endothelial cell density (ECD) compared to healthy eyes, whereas others observed no significant change. ${ }^{9-12}$ Similarly, several publications in the literature report a decrease in the hexagonal cell percentage (HCP) and an increase in the coefficient of variation (CV) in $\mathrm{KC}$ cases, while some studies report no change. ${ }^{9-12}$ Reasons for the different results may be related to the number of patients included in the studies, the distribution of the age range of the patients, the stages of keratoconus, and the previous treatment approaches.

In literature, most of the studies were frequently evaluated newly diagnosed young patient groups. The progression of $\mathrm{KC}$ is highly variable; It can progress rapidly for 3-5 years and then stop, or in some cases it may progress intermittently over a longer period. Progression is most often expected between the ages of 10 and 20, with less progression between the ages of 20 and 30, and over the age of 30 there is usually no progress. ${ }^{1,3,5}$

In our study, we aimed to evaluate the corneal endothelial cell parameters and to investigate the correlation with corneal topographic parameters in middle-aged KC patients who did not have any treatment. In this way, we aimed to obtain clearer information about the permanent effect of KC on the endothelium by performing endothelial analysis in the older age group.

\section{Methods}

The datas of the patients who were followed up in the cornea department due to KC between 2018-2020 were retrospectively analyzed. Mid-decade (4-5) patients who had not used contact lenses or topical medications before, had not undergone any laser or surgical procedure, and had no history of hydrops were included in the study. Patients who applied to the ophthalmology clinic for various reasons and did not have any ocular surgery, contact lens use history, corneal pathology, and had a spherical equivalent refractive error of less than 2 diopters (D) were randomly selected as the control group. The study was conducted in accordance with the ethical principles included in the Helsinki Declaration and informed consent forms were obtained from the patients (IRB:71522473/050.01.04/67).

Corneal topography and specular microscopy were performed in all cases after a detailed ophthalmologic examination, including best corrected visual acuity (BCVA) measured with Snellen chart, anterior segment and fundus examinations. 
Corneal topography measurements were obtained with a Galilei G4 dual scheimpflug analyzer (Ziemer Ophthalmic Systems AG, Port, Switzerland). Galilei dual scheimpflug analyzer provides more accurate anterior curvature topographic data using the Placido disc in addition to the data obtained from Scheimpflug cameras. Measurements were taken after the cornea was centralized and then the patient blinked twice to provide an optically smooth tear film layer on the corneal surface. Scans approved by the software with sufficient image quality were accepted; parameters such as mean simulated keratometry (SimK), K1, K2, anterior chamber depth (ACD), pachymetry (central, thinnest), and corneal astigmatism values were obtained. Patients were divided into stages according to mean keratometric values (Mild < 45D, Moderate 45-52 D, Severe > 52D, Advanced > 62 D).

Specular microscopy measurements were obtained with CEM 530 specular microscopy (NIDEK, Japan) device. With the automatic alignment and auto focus feature of the device, analysis was performed on the sections that was taken from the central cornea. ECD, CV (polymegatism, \%) and HCP were recorded.

Corneal topography parameters and endothelial cell features were compared between $\mathrm{KC}$ and healthy eyes. The correlation between topographic parameters and endothelial cell features was analyzed.

The data were analyzed with the SPSS (Statistical Package for Social Sciences) 22.0 program (SPSS Inc. Chicago, USA). The variables were investigated using analytical methods (Kolmogorov-Smirnov test) to determine whether they were normally distributed or not. Descriptive analyses were presented using means and standard deviations for normally distributed variables. These parameters were compared using the Student-T test for the healthy and KC groups. Pearson test was performed for evaluation of the correlation and statistical significance between ECD and keratometric parameters. Differences were considered statistically significant when $p$ value was less than 0.05 .

\section{Results}

Thirty- six eyes of $21 \mathrm{KC}$ patients ( 11 females, 10 males) and 36 healthy eyes ( 17 females, 19 males) in the middle decade (4th-5th) were included in the study. The mean age in the KC group was $38.6 \pm 6.0$ $(32-55)$ and the control group was $37.8 \pm 4.2(31-51)$ years; groups were similar in terms of age and gender ( $\mathrm{p}: 0.420)$.

Corneal topography parameters such as SimK, K1, K2, ACD, pachymetry values (central, thinnest), corneal astigmatism values were found to be significantly different in the KC (Table 1). 
Table 1

Corneal topography and specular microscopy parameters of patients and control group.

\begin{tabular}{|c|c|c|c|}
\hline & \multirow{2}{*}{$\begin{array}{l}\text { KC } \\
n: 36\end{array}$} & \multirow{2}{*}{$\begin{array}{l}\text { Control } \\
\text { N:36 }\end{array}$} & \multirow[t]{2}{*}{ p } \\
\hline & & & \\
\hline K1 (D) & $46.2 \pm 2.7$ & $42.7 \pm 1.2$ & $<0.001$ \\
\hline K2 (D) & $49.6 \pm 3.3$ & $43.5 \pm 1.2$ & $<0.001$ \\
\hline $\operatorname{Sim} K(D)$ & $47.9 \pm 2.9$ & $43.1 \pm 1.2$ & $<0.001$ \\
\hline Corneal astigmatism (D) & $3.3 \pm 1.5$ & $0.8 \pm 0.39$ & \\
\hline Posterior flat K (D) & $-7.02 \pm 0.6$ & $-6.02 \pm 0.2$ & $<0.001$ \\
\hline Posterior steep K (D) & $-7.7 \pm 0.7$ & $-6.3 \pm 0.2$ & $<0.001$ \\
\hline Posterior SimK (D) & $-7.3 \pm 0.6$ & $-6.2 \pm 0.2$ & $<0.001$ \\
\hline $\mathrm{ACD}(\mathrm{mm})$ & $3.1 \pm 0.2$ & $2.9 \pm 0.3$ & 0.001 \\
\hline $\operatorname{CCT}(\mu)$ & $484.3 \pm 37.4$ & $544.7 \pm 26.7$ & $<0.001$ \\
\hline Thinnest CCT $(\mu)$ & $449.08 \pm 39.1$ & $531.2 \pm 28.2$ & $<0.001$ \\
\hline ECD (cells / mm²) & $2772.2 \pm 174.8$ & $2741.03 \pm 300.9$ & 0.621 \\
\hline CV & $30.7 \pm 5.2$ & $28.6 \pm 3.4$ & 0.058 \\
\hline HCP (\%) & $63.5 \pm 7.2$ & $67.4 \pm 5.02$ & 0.014 \\
\hline
\end{tabular}

ECD was $2772 \pm 174$ cells / $\mathrm{mm}^{2}$ in the $\mathrm{KC}$ group and $2741 \pm 300$ cells $/ \mathrm{mm}^{2}$ in the control group, and there was no statistical difference between the groups (p: 0.621). HCP was $63.5 \pm 7.2,67.4 \pm 5.2$ in KC and healthy eyes, respectively (p: 0.014$)$; CV was $30.7 \pm 5.2,28.6 \pm 3.4$, respectively (p: 0.058$)$ (Table 1 ).

Keratoconus eyes were classified according to keratometric values; 22 eyes were mild, 10 eyes were moderate, and 4 eyes were severe, and there was no significant difference between the groups in terms of endothelial cell properties ( $\mathrm{p}$ : 0.744) (Table 2). Corneal topography parameters such as K1, K2, SimK, CCT, ACD did not correlate with ECD in keratoconus patients (Table 3) (Fig. 1). 
Table 2

Comparision of specular microscopy parameters according to KC stage

\begin{tabular}{|lllll|}
\hline & Mild & Moderate & Severe & P \\
& N:22 & N:10 & N:4 & \\
\hline ECD & $2792.1 \pm 189.1$ & $2748.5 \pm 161.3$ & $2724.3 \pm 153.3$ & 0.744 \\
\hline CV & $30.3 \pm 4.2$ & $29.4 \pm 5.5$ & $37.0 \pm 6.9$ & 0.772 \\
\hline HCP & $64.1 \pm 6.9$ & $64.5 \pm 7.7$ & $57.3 \pm 6.4$ & 0.294 \\
\hline
\end{tabular}

Table 3

Correlation between ECD and keratometric parameters

\begin{tabular}{|lll|}
\hline & $\mathbf{r}$ & $\mathbf{p}$ \\
\hline SimK & -0.099 & 0.603 \\
$\mathbf{K} 1$ & -0.124 & 0.415 \\
K2 & -0.190 & 0.314 \\
ACD & 0.013 & 0.948 \\
\hline CCT & -0.180 & 0.341 \\
\hline
\end{tabular}

\section{Discussion}

Our study focused on middle-aged patients in whom KC progression was not expected. We compared their corneal endothelial cell parameters with those of similarly aged healthy cases. We found that endothelial cell morphology was significantly affected, although there was no significant difference in ECD.

ECD amounts to 3500 cells $/ \mathrm{mm}^{2}$ at birth and decreases by $0.6 \%$ per year to 2600 cells $/ \mathrm{mm}^{2}$ with age. Corneal endothelial cells are typically hexagonal and present a uniform sequence. However, the number of endothelial cells decreases and their size and shape also change due to aging, trauma, surgery, and various corneal diseases. ${ }^{12}$ 
Changes in the endothelium in $\mathrm{KC}$ eyes may be affected by the age of onset of $\mathrm{KC}$, progression status, degree of asymmetry, amount of stromal thinning, and type and location of the cone area. ${ }^{12}$ The pathophysiology of endothelial cell damage may be related to factors such as microscopic ruptures in Descemet's membrane in the ectatic region, ultraviolet damage due to stromal thinning, and oxidative stress. ${ }^{5}$ Another cause of endothelial cell damage may be the transient increase in intraocular pressure that develops due to compressive and distending forces on the anterior and posterior corneal surfaces after mechanical trauma, such as eye scratching and rubbing. ${ }^{13}$

Previous histological examinations of $\mathrm{KC}$ corneal buttons obtained by penetrating keratoplasty revealed changes in endothelial density and morphology. One of these studies attributed these changes to contact lens wear ${ }^{14}$, while another proposed that they depended on the severity and duration of KC. ${ }^{15}$

Confocal microscopy studies reported lower ECD; however, some studies observed no significant change, and one study even observed an increase. ${ }^{6-8}$ These different results may be attributed to the varied locations of corneal area examination; evaluations of the central cornea, not the cone area, may have caused these conflicting findings. Studies reporting a decrease in ECD, polymegatism, and pleomorphism observed that these changes were more pronounced in areas adjacent to ruptures in Descemet's membrane. ${ }^{6,12}$

As in the case of confocal microscopy studies, the results from specular microscopy studies are conflicting. Some publications reported that ECD decreased compared to healthy eyes, whereas others observed no change. ${ }^{9-12}$ Interestingly, on average, the subjects of the majority of these previous works were newly diagnosed young patients. In our study, the mean age of the subjects was $38.6 \pm 6.0$ years; in other words, the average age of the participants in our work was higher than that of patients in the literature.

Gökçınar et al. conducted a study consisting of 70 eyes and a mean patient age of 31.06 years. They reported that $\mathrm{CV}$ was significantly higher in the $\mathrm{KC}$ group compared to the control group, while ECD and HCP were similar in both groups. ${ }^{17}$ Bahadır et al. found a significant decrease in ECD but no significant difference in cell morphology in their study consisting of 44 eyes and a mean patient age of 28.1 years. ${ }^{18}$ Moreover, a previous comparison of KC patients who wear contact lenses with normal cases reported increased polymegatism and pleomorphism in the KC cases. ${ }^{19}$ Similar results were found by researchers comparing $\mathrm{KC}$ cases with and without contact lens wear. ${ }^{20}$ These results may be related to hypoxic stress caused by contact lens wear. As these publications show, the use of contact lenses can affect the results; thus, we excluded patients with a history of contact lens wear from our study.

Our study classified KC eyes according to keratometric values. There was no significant difference between the groups in terms of endothelial cell morphology. However, an increase in CV and a decrease in HCP were detected in severe cases, although the results were not statistically significant. Stronger results could have been obtained, if the number of severe cases had been much. The results of our study agree with those of Gökçınar et al., who reported no significant differences in terms of endothelial cell 
morphology according to KC stage. ${ }^{18}$ However, Bozkurt et al. reported that ECD significantly decreased with the progression of $\mathrm{KC}$ in their study, which consisted of 391 eyes and a mean patient age of $24.2 \pm$ 7.7 years. ${ }^{10}$ Goebels et al. observed that ECD decreased and CV increased with the progression of keratoconus in their work containing $712 \mathrm{KC}$ cases. $^{9}$

Our study comprised only those patients who had not undergone a surgical procedure previously and had no contact lens use history. When the participants were classified according to the KC stage, the number of patients in the severe stages was lower. Notably, it is difficult to achieve such a patient group, since patients with $\mathrm{KC}$ have typically undergone various surgical procedures for visual rehabilitation. It is possible that our results may have differed if our work would have included more advanced stage patients.

Our study has several limitations. First, due to advances in technology, keratoconus is diagnosed earlier and more accurately today, and various treatments can be applied in the indicated cases. Since the patient group in our study was quite specific, it was not possible to include a sufficient number of patients. Additionally, specular microscopy was performed on the central cornea in all our patients. More accurate results would have been achieved by evaluating the area closer to the cone region.

Our results showed that endothelial cell morphology is significantly affected in middle-aged keratoconus patients who have not been treated. These results should be supported by additional research on a larger number of cases.

\section{Declarations}

\section{Compliance with Ethical Standards:}

Funding: This study was not funded by any company.

\section{Conflict of Interest:}

Author Emine Dogan declares that he has no conflict of interest.

Author Burcin Cakir declares that she has no conflict of interest.

Author Nilgun Ozkan Aksoy declares that she has no conflict of interest.

Author Gursoy Alagoz declares that he has no conflict of interest.

\section{Compliance with Ethical Standarts}

Disclosure of potential conflict of interest: All authors declare that they have no conflict of interest.

Ethics approval/Research involving Human Participants: Prior ethical approval from the Sakarya University Institutional Review Board (IRB:71522473/050.01.04/67) was taken. The study was performed 
in adherence to the 1964 Declaration of Helsinki.

Informed Consent: Written informed consent was obtained from each subject or from parents of each subject, in the study.

Consent for publication: Patients or parents of patients signed informed consent regarding publishing their data

Availability of data and material: not applicable

Code availability: not applicable

\section{References}

1. Romero-Jiménez M, Santodomingo-Rubido J, Wolffsohn JS. Keratoconus: a review. Cont Lens Anterior Eye. 2010;33(4):157-66; 205. doi: 10.1016/j.clae.2010.04.006. PMID: 20537579.

2. Hashemi H, Heydarian S, Hooshmand E, et al. The Prevalence and Risk Factors for Keratoconus: A Systematic Review and Meta-Analysis. Cornea. 2020;39(2):263-270. doi:

10.1097/ICO.0000000000002150. PMID: 31498247.

3. Gokhale NS. Epidemiology of keratoconus. Indian J Ophthalmol. 2013;61(8):382-3. doi: 10.4103/0301-4738.116054

4. Davidson AE, Hayes S, Hardcastle AJ, Tuft SJ. The pathogenesis of keratoconus. Eye (Lond). 2014;28(2):189-95. doi: 10.1038/eye.2013.278.

5. Mas Tur V, MacGregor C, Jayaswal R, O'Brart D, Maycock N. A review of keratoconus: Diagnosis, pathophysiology, and genetics. Surv Ophthalmol. 2017 ;62(6):770-783. doi:

10.1016/j.survophthal.2017.06.009.

6. Niederer RL, Perumal D, Sherwin T, McGhee CN. Laser scanning in vivo confocal microscopy reveals reduced innervation and reduction in cell density in all layers of the keratoconic cornea. Invest Ophthalmol Vis Sci. 2008;49(7):2964-70. doi: 10.1167/iovs.07-0968.

7. Uçakhan 00 , Kanpolat A, Ylmaz N, Ozkan M. In vivo confocal microscopy findings in keratoconus. Eye Contact Lens. 2006;32(4):183-91. doi: 10.1097/01.icl.0000189038.74139.4a

8. Mocan MC, Yilmaz PT, Irkec M, Orhan M. In vivo confocal microscopy for the evaluation of corneal microstructure in keratoconus. Curr Eye Res. 2008 ;33(11):933-9. doi: 10.1080/02713680802439219.

9. Goebels S, Eppig T, Seitz B, Szentmàry N, Cayless A, Langenbucher A. Endothelial alterations in 712 keratoconus patients. Acta Ophthalmol. 2018;96(2):e134-e139. doi: 10.1111/aos.13471.

10. Bozkurt B, Yılmaz M, Meşen A, Kamış Ü, Ekinci Köktekir B, Okudan S. Correlation of Corneal Endothelial Cell Density with Corneal Tomographic Parameters in Eyes with Keratoconus. Turk J Ophthalmol. 2017;47(5):255-260. doi: 10.4274/tjo.22800. Epub 2017 Oct 27.

11. Timucin OB, Karadag MF, Cinal A, Asker M, Asker S, Timucin D. Assessment of corneal endothelial cell density in patients with keratoconus not using contact lenses. Cont Lens Anterior Eye. 
2013;36(2):80-5. doi: 10.1016/j.clae.2012.10.081.

12. McMonnies CW. Corneal endothelial assessment with special references to keratoconus. Optom Vis Sci. 2014;91(6):124-34. doi: 10.1097/OPX.0000000000000271.

13. McMonnies $\mathrm{CW}$. Mechanisms of rubbing-related corneal trauma in keratoconus. Cornea 2009;28:607Y15.

14. Halabis JA. Analysis of the corneal endothelium in keratoconus. Am J Optom Physiol Opt. 1987;64(1):51-3. doi: 10.1097/00006324-198701000-00009. PMID: 3826278.

15. Sturbaum CW, Peiffer RL Jr. Pathology of corneal endothelium in keratoconus. Ophthalmologica. 1993;206(4):192-208. doi: 10.1159/000310390. PMID: 8278166.

16. Hollingsworth JG, Efron N, Tullo AB. In vivo corneal confocal microscopy in keratoconus. Ophthalmic Physiol Opt 2005;25:254Y60.

17. Gökçınar NB, Akbulut Y, Oğurel T, Koç S, Onaran Z. The Comparison of Corneal Endothelial Cell Properties with the Topographic Ectasia Indexes in Keratoconus. Kırıkkale Üniversitesi Tıp Fakültesi Dergisi 2019;21(2):218-225. doi:10.24938/kutfd.555896

18. Bahadır AE, Aktay S, Coşar B, Acar S. Comparision of specular microscopy and pachymetry findings of keratoconic and normal eyes. Turkiye Klinikleri J Ophthalmol . 2008;17(4):227-32.

19. Matsuda M, Suda T, Manabe R. Quantitative analysis of endothelial mosaic pattern changes in anterior keratoconus. Am J Ophthalmol 1984;98:43Y9.

20. Edmonds CR, Wung SF, Husz MJ, Pemberton B. Corneal endothelial cell count in keratoconus patients after contact lens wear. Eye Contact Lens 2004;30:54Y8.

\section{Figures}




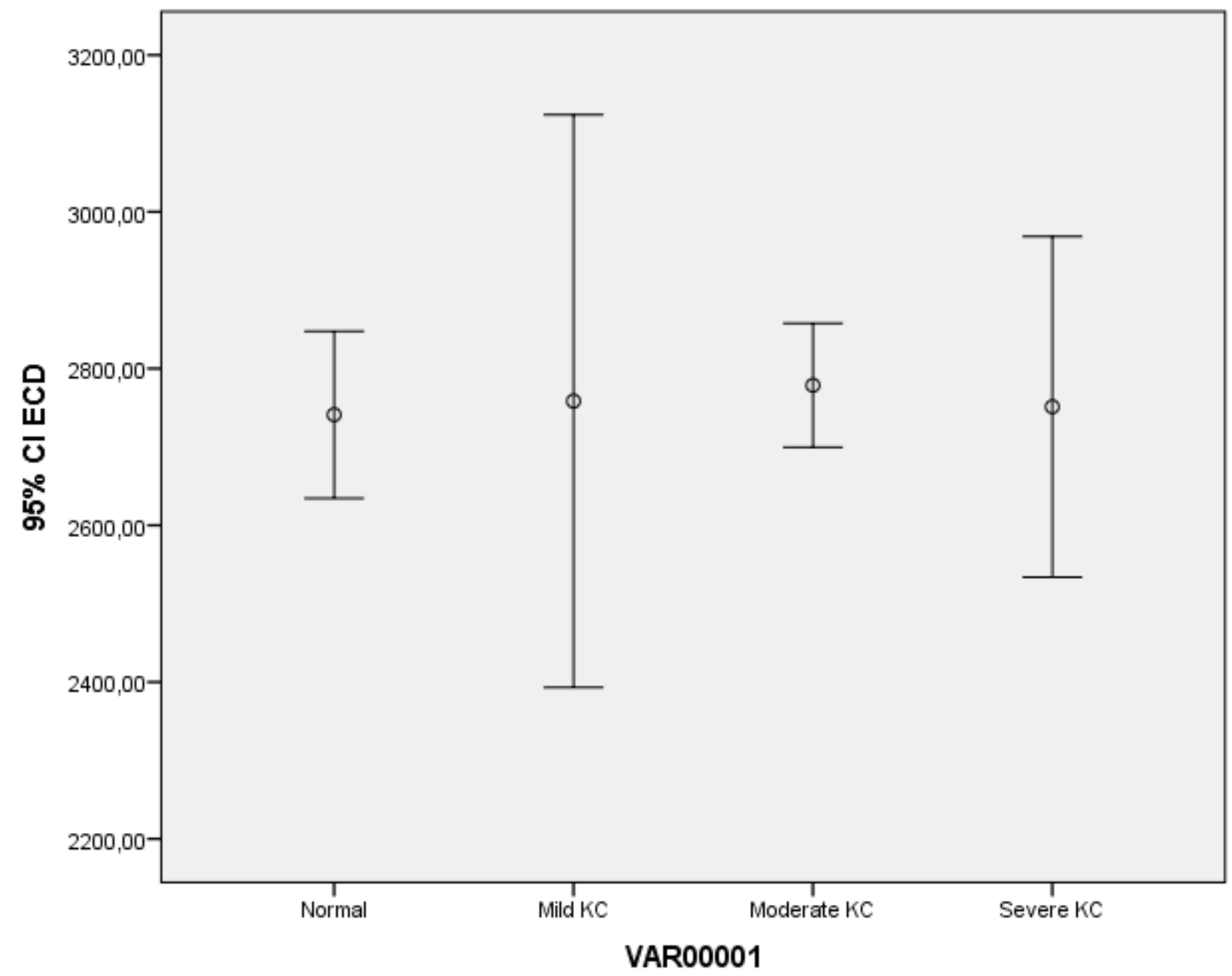

Figure 1

The mean ECD in normal cases and eyes with mild, moderate and severe keratoconus 